\title{
Local Treatment of the Axilla in Early Breast Cancer: Concepts from the National Surgical Adjuvant Breast and Bowel Project B-04 to the Planned Intergroup Sentinel Mamma Trial
}

\author{
Toralf Reimer Steffi Hartmann Angrit Stachs Bernd Gerber
}

Department of Obstetrics and Gynecology, University of Rostock, Germany

\section{Keywords}

Breast cancer · Axilla · Surgery · Radiotherapy · INSEMA

\section{Summary}

Local treatment of the axilla in clinically node-negative, early-stage breast cancer patients has been hotly debated after the release of the American College of Surgeons Oncology Group (ACOSOG) Z0011 findings. However, this review does not focus on the 'Z0011-eligible' patients alone, because this subgroup represents a minority of our patients undergoing breast-conserving surgery (BCS) and sentinel lymph node biopsy (SLNB). The following topics are discussed: axillary diagnostics, timing of axillary procedures in the neoadjuvant setting, long-term follow-up of SLNB trials, omission of axillary surgery in randomized trials, management of the involved axilla with low tumor volume, positive sentinel lymph nodes and BCS, involved sentinel lymph nodes and mastectomy, and axillary radiotherapy. Finally, the current innovative study concepts (i.e. Sentinel Node versus Observation after Axillary Ultrasound (SOUND) and Intergroup Sentinel Mamma (INSEMA)) including patients with axillary observation alone in clinically node-negative women are presented.

\section{Introduction}

At the moment, local treatment of the axilla in clinically node-negative, early-stage breast cancer patients is hotly debated after the release of the American College of Surgeons Oncology Group (ACOSOG) Z0011 [1, 2] and European Organisation for Research and Treatment of Cancer (EORTC) AMAROS trial data [3]. Highlight of this controversial discussion is the point-counterpoint review in the Cancer
Research issue from December 15, 2013 [4-7]. Focus of these pro and contra statements is the question as to how radically the Z0011 findings can be applied to the routine clinical practice.

In a table, Morrow summarizes a series of prospective randomized trials, illustrating several key points relevant to axillary treatment [4]. In the National Surgical Adjuvant Breast and Bowel Project (NSABP) B-04 study [8], where no irradiation and no systemic therapy was given, 1 axillary recurrence was observed for every 2.2 patients with disease left in the axilla. In contrast, in both the NSABP B-32 [9] and the International Breast Cancer Study Group (IBCSG) 23-01 [10] studies, this ratio decreased to 1 recurrence per 13 or 14 patients with residual nodal disease due to chemo- and radiotherapy use in more than $70 \%$ of the patients. Further reduction in regional recurrence ( 1 recurrence per 30 patients with $\mathrm{pN}+$ status at axillary lymph node dissection (ALND)) was seen in the ACOSOG Z0011 trial [1,2], where a greater proportion of the patients received postoperative adjuvant therapy.

In a figure of the counterpoint review, Sabel [6] presents a comprehensive algorithm for the management of cT1-T2 patients with invasive breast cancer, incorporating a multidisciplinary discussion. Of note, patients who require or desire mastectomy and sentinel lymph node biopsy (SLNB) are included in this flow chart. Late breaking American Society of Clinical Oncology (ASCO) abstracts for postoperative radiotherapy like AMAROS [3] and MA.20 presentations [11] were considered for the decision tree. These data may help to identify several 'Z0011-ineligible' patients who may still safely avoid ALND, such as mastectomy patients with involved sentinel lymph node (SLN) for whom postmastectomy radiotherapy (PMRT) is being considered (and an axillary field could be added). However, the most critical point of the described algorithm is the identification and management of 'Z0011-eligible' patients.

\section{KARGER}

Fax +497614520714

Information@Karger.com www.karger.com

\section{$\begin{array}{ll}\text { (C) 2014 S. Karger GmbH, Freiburg } & \text { Karger } \\ 1661-3791 / 14 / 0092-0087 \$ 39.50 / 0 & \text { Open access }\end{array}$ \\ This is an Open Access article licensed under the terms of the} Creative Commons Attribution-NonCommercial 3.0 Unported license (CC BY-NC) (www.karger.com/OA-license), applicable to the online version of the article only. Distribution permitted for non-commercial purposes only.
Toralf Reimer, MD PhD

Department of Obstetrics and Gynecology

University of Rostock, Klinikum Suedstad

Suedring 81, 18059 Rostock, Germany

toralf.reimer@med.uni-rostock.de 
Data to support the multidisciplinary discussion regarding axillary treatment of clinically node-negative patients are summarized in this review. We do not focus on the 'Z0011eligible' patients alone, because this subgroup represents a minority of our patients undergoing breast-conserving surgery (BCS) and SLNB in T1/T2 carcinomas. An analysis at the Memorial Sloan-Kettering Cancer Center (MSKCC) revealed that only $13.3 \%$ ( 287 of 2,157$)$ of the patients were 'Z0011 eligible' between August 2010 and November 2012 [12]. A second important fact of this MSKCC paper is the low SLN-positive rate of $17.6 \%$ in the analyzed BCS cohort. This finding has been confirmed by another unicentric evaluation of 1,140 patients (T1/T2) with an SLN-positive rate of $13 \%$ [13]. All of these patients at the Mayo Clinic Rochester were clinically node-negative by preoperative axillary ultrasound (AUS) with or without fine-needle aspiration (FNA) biopsy. Recently, we have published our data from the University Hospital Rostock with an SLN-positive rate of 21.1\% [14].

The reported SLN-positive rates of less than $22 \%$ in patients with $\mathrm{BCS}$ in the era of mammographic screening raise questions on the role of SLNB itself. Therefore, new trials were designed comparing SLNB versus observation when physical exam and AUS are negative in patients with BCS. The ongoing Sentinel Node versus Observation after Axillary Ultrasound (SOUND) trial and the planned Intergroup Sentinel Mamma (INSEMA) trial are discussed at the end of the review.

\section{Axillary Diagnostics}

Over the last 3 decades, many studies have shown the advantage of AUS to detect lymph node metastases in women with breast cancer. In a systematic review including 16 studies, the sensitivity ranged from $26.4 \%$ (95\% confidence interval (CI): $15.3-40.3 \%$ ) to $75.9 \%$ (95\% CI: $56.4-89.7 \%$ ) if morphological criteria were used. In these studies, the specificity varied between 88.4 and $98.1 \%$. The combination of AUS and FNA led to a specificity improvement to nearly $100 \%$, but the sensitivity could not be substantially increased (range between 30.6 and $62.9 \%$ ) [15]. A recent meta-analysis from Houssami et al. [16] included 31 studies dealing with ultrasound-guided needle biopsy (UNB) in preoperative axillary staging. Data from 2,874 UNBs of 6,166 breast cancer patients were analyzed. The median prevalence of lymph node metastases was $47.2 \%$. Modeled estimates for UNB showed a sensitivity of $79.6 \%$ (95\% CI: $74.1-84.2 \%)$ and a specificity of 98.3\% (95\% CI: 97.2-99.0\%). However, subgroup analysis revealed a higher diagnostic accuracy in patients with a higher underlying risk of lymph node metastases [16]. Moreover, uncertainty remains as to which ultrasound criteria including size, morphology, cortical thickness, and vascularity should be used to declare a lymph node as positive. Of these criteria, a longitudinal-transverse axis ratio $(\mathrm{LT}$ ratio $)<2$, eccentric cor- tical thickening, and/or an absent fatty hilum as well as higher peripheral vascularity are reported as the most reliable criteria to predict lymph node metastases $[17,18]$. The diagnostic performance of new imaging techniques like fluorodeoxyglucose positron emission tomography combined with computed tomography (FDG PET/CT) and magnetic resonance imaging (MRI) is similar to that of AUS [19, 20]. With regard to the higher costs and possible side effects, PET/CT and MRI do not have a place in routine axillary staging. Finally, we have to take into account that exclusion of nodal metastatic infiltration is impossible with any imaging technique in about $25 \%$ of nodal metastases due to a size of $\leq 5 \mathrm{~mm}$, which is below the reliability for detection [14].

\section{Timing of Axillary Procedures in the Neoadjuvant Setting}

Neoadjuvant systemic therapy is established for locally advanced breast cancer and increasingly used for early-stage disease as well [21]. The current recommendation is to perform SLNB in clinically and/or histologically/cytologically node-negative patients prior to systemic therapy, and axillary level I/II dissection in clinically and/or histologically/cytologically node-positive patients after neoadjuvant therapy [22, 23]. Nevertheless, the timing of axillary surgery in the neoadjuvant setting is controversial.

There is growing evidence that SLNB following neoadjuvant systemic therapy in patients without evident cancer in their axilla is acceptable and an additional surgical procedure could therefore be avoided in these women. To date, 4 metaanalyses that access the accuracy of SLNB after neoadjuvant chemotherapy have been published [24-27]. Although most of the included studies are limited by small size, retrospective design, and wide variation in results, the sentinel identification rates and false-negative rates determined were similar to those seen in patients undergoing SLNB before chemotherapy [28]. Anyway, because the lymphatic drainage from the breast could be impaired by primary systemic therapy and because the tumor regression pattern in the axilla is unknown, performing SLNB not before neoadjuvant therapy in clinically node-negative patients can be discussed with patients who wish to avoid 2 separate operations, but should not be recommended as routine procedure.

The second controversy deals with the potential to perform SLNB and to abandon level I/II dissection with its possible harms in patients with initial node-positive disease who are downstaged by neoadjuvant chemotherapy to cN0 and present with histologically negative SLN. Arm C of the prospective, multicentric SENTInel NeoAdjuvant (SENTINA) trial investigated the feasibility and accuracy of SLNB for this cohort of patients $(n=592)$. The sentinel detection rate was $80.1 \%$ and the false-negative rate was $14.2 \%$. Although the detection rate and false-negative rate are inferior compared
88

Breast Care 2014;9:87-95
Reimer/Hartmann/Stachs/Gerber 
to patients undergoing SLNB before neoadjuvant treatment, the detection rate was increased by a combined detection procedure (radiocolloid and blue dye) compared with the use of a radiocolloid alone $(87.7 \%$ vs. $77.4 \%)$, and the false-negative rate decreased depending on the number of sentinel nodes removed (1 node $24.3 \%, 2$ nodes $18.5 \%, 3$ nodes $7.3 \%$ ) [29]. These findings are supported by the ACOSOG Z1071 (Alliance) trial, a prospective multicenter study including women initially presenting with biopsy-proven $\mathrm{cN} 1$ breast cancer. For these patients undergoing both SLNB and level I/II dissection following chemotherapy, a false-negative rate of $12.6 \%$ was determined if 2 or more sentinel nodes were removed. The false-negative rate was significantly lower when dual mapping was used compared to a single mapping agent (10.8\% vs. $20.3 \%)$ and when the number of removed sentinel nodes was $\geq 3$ ( 2 nodes $21.1 \%$ vs. $\geq 3$ nodes $9.1 \%$ ) [30]. These studies demonstrate that when 3 or more sentinel nodes are harvested and dual sentinel detection procedures are used, the false-negative rate and the detection rate for initially clinically node-positive patients at SLNB after initial systemic treatment are comparable to those in initially node-negative patients. However, at the moment, we have no data regarding locoregional control and survival, and therefore further trials are needed to clarify which patients can be spared from ALND after initially lymph node-positive disease in the neoadjuvant setting.

\section{Long-Term Follow-Up of SLNB Trials}

The SLNB technique in breast cancer surgery was first described in 1994 with the aim to minimize morbidity associated with conventional ALND [31]. A current meta-analysis investigated the clinical effectiveness and safety of SLNB compared to ALND including only randomized controlled trials [2, 9, 32-37]. In the 8 included studies, a total of 8,560 patients were eligible for analysis (SLNB group $\mathrm{n}=4,301$; ALND group $n=4,259$ ). The sensitivity of SLNB ranged from 93 to $97.1 \%$ and the false-negative rate from 5 to $22.9 \%$. No statistical difference in overall survival (OS), disease-free sur- vival (DFS), and regional lymph node recurrence was found between the SLNB and ALND groups [38]. The false-negative rate of up to $22.9 \%$ raises the concern for recurrence due to residual metastases, but in practice the rates of axillary lymph node recurrence range from 0 to $3 \%[9,32,34,36]$.

As expected, the postoperative morbidity (lymphedema, numbness or paresthesia, impairment of arm mobility) was significantly higher in the ALND group [38]. The rate of lymphedema was reduced from $10-20 \%$ to $5-7 \%$, arm numbness/pain from 31 to $11 \%$ [39]. Long-term follow-up showed that SLNB was associated with less morbidity than ALND [40].

Because of these conclusive data, axillary SLNB should be routine procedure in patients who have no palpable or ultrasound evidence of axillary metastases. Contraindications for SLNB are suspicious axillary lymph nodes and inflammatory breast cancer [23]. In spite of concerns regarding an impaired lymphatic drainage from the breast because of prior extensive breast surgery or previous axillary surgery, SLNB seems to be safe and feasible in these cases [41, 42]. In cases with doubtful sonographic findings, axillary FNA cytology or UNB is indicated. Patients with clinically, sonographically suspicious, or biopsy-proven positive axillary nodes are still candidates for ALND.

\section{Omission of Axillary Surgery: Published Randomized Trials}

Prior to establishing the efficacy and safety of SLNB, trials that compared axillary dissection versus no axillary surgery and versus axillary radiotherapy (ART) were conducted to avoid possible side effects of level I/II dissection.

Four prospective trials randomized breast cancer patients to standard axillary surgery versus no axillary surgery (table 1). These studies show a low rate of axillary recurrences, even in the arms without axillary surgery, although axillary lymph node involvement in the ALND group ranged from 23 to $40 \%$. No significant differences between the groups with or without ALND could be found for DFS and OS [8, 43-45].

Table 1. Prospective randomized clinical trials comparing ALND versus no axillary surgery

\begin{tabular}{|c|c|c|c|c|c|c|}
\hline Author, study & Patients & $\mathrm{N}$ & $\begin{array}{l}\text { Follow-up, } \\
\text { years }\end{array}$ & $\begin{array}{l}\text { Axillary } \\
\text { recurrence }\end{array}$ & DFS & OS \\
\hline $\begin{array}{l}\text { Fisher et al. (2002) [8], } \\
\text { NSABP B-04 }\end{array}$ & $\begin{array}{l}\mathrm{cN} 0 \text {, any age, radical ME vs. } \\
\text { ME alone vs. ME + irradiation, } \\
\text { no systemic therapy }\end{array}$ & 1,079 & 25 & $\begin{array}{l}18.6 \% \text { in } \\
\text { ME-alone arm }\end{array}$ & $\begin{array}{l}19 \% \text { vs. } 19 \% \text { vs. } \\
13 \% ; p=0.65\end{array}$ & $\begin{array}{l}25 \% \text { vs. } 26 \% \text { vs. } \\
19 \% ; p=0.68\end{array}$ \\
\hline $\begin{array}{l}\text { International Breast Cancer } \\
\text { Study Group (2006) [43], } \\
\text { IBCSG 10-93 }\end{array}$ & pT1-2a $, \mathrm{cN} 0, \geq 60$ years, Tam & 473 & 6.6 & $\begin{array}{l}0.9 \% \text { vs. } 2.5 \% \text {; } \\
\text { n.s. }\end{array}$ & $\begin{array}{l}67 \% \text { vs. } 66 \% \\
p=0.69\end{array}$ & $\begin{array}{l}75 \% \text { vs. } 73 \% \\
p=0.77\end{array}$ \\
\hline Martelli et al. (2012) [45] & $\begin{array}{l}\mathrm{cN} 0, \mathrm{pT} 1 / \mathrm{T} 2(\leq 2.5 \mathrm{~cm}) \\
\geq 65 \text { years, Tam }\end{array}$ & 219 & 15 & 0 vs. $3.6 \%$ & DDFS $\mathrm{p}=0.95$ & $\mathrm{p}=0.64$ \\
\hline $\begin{array}{l}\text { Agresti et al. (2013) [44], } \\
\text { INT09/98 }\end{array}$ & $\begin{array}{l}\text { cT1N0, 30-65 years, Tam, } \\
\pm \text { chemotherapy }\end{array}$ & 565 & 10 & 0 vs. $9 \%$ & $\begin{array}{l}92.4 \% \text { vs. } 91.3 \% \\
p=0.9\end{array}$ & $\begin{array}{l}93.3 \% \text { vs. } 91.5 \% \\
p=0.78\end{array}$ \\
\hline
\end{tabular}

${ }^{a} 42 \%$ of the patients with tumors $>2 \mathrm{~cm}$.

$\mathrm{ME}=$ Mastectomy, Tam $=$ tamoxifen, n.s. $=$ non-significant, DDFS $=$ distant disease-free survival. 
Notably, none of the mentioned randomized trials investigated ALND versus no axillary treatment including patients with suspicious axillary lymph nodes.

Johansen et al. [46] reported no significant differences regarding DFS and OS after 50 years of follow-up for patients treated with radical mastectomy including ALND or simple mastectomy plus ART $(n=425)$. Veronesi et al. [47] randomized patients treated by BCS without palpable lymph nodes $(\mathrm{n}=435)$ to ART versus no axillary treatment and found very low rates of axillary recurrence after a median follow-up of 63 months $(0.5 \%$ vs. $1.5 \%, \mathrm{p}=0.3)$ and similar 5-year DFS rates for both groups (96.9\% vs. 95.1\%). A third available randomized trial compared patients with tumors of less than $3 \mathrm{~cm}$ and $\mathrm{cN} 0$ receiving ALND or ART $(\mathrm{n}=658)$ [48]. Although axillary recurrences were more frequent in the ART group at 15 years of follow-up ( $1 \%$ vs. 3\%, p = 0.04), DFS (64.3\% vs. $65.5 \%)$ and OS (75.5\% vs. $73.8 \%)$ were similar for both groups. ART in the setting of no prior axillary surgery has generally been associated with less morbidity. The incidence of morbidity after SLNB combined with ART has not been well characterized [49]. Because in patients without SLN metastases ART would result in an overtreatment, primary ART in patients without evidence of axillary metastases should not be conducted routinely [39].

Summarizing these data, avoiding axillary treatment in patients with clinically and sonographically insuspicious lymph nodes seems to be a safe option. Further studies are needed to define subgroups of patients who do not profit from axillary treatment and can be prevented from its possible side effects. In patients with suspicious axillary lymph nodes, ALND remains the standard treatment [22,23].

\section{Management of the Involved Axilla with Low Tumor Volume}

Since the introduction of SLNB, pathological examination of lymph nodes has become more intensive, including routine use of a step-sectioning procedure, with or without immunohistological staining [50]. This resulted in an increased detection of small metastatic tumor deposits [51]. Whereas in the pre-SLN era metastatic deposits of $2 \mathrm{~mm}$ or smaller were classified as lymph node-positive micrometastatic disease, from 2002 up to now a distinction has been made between isolated tumor cells (ITCs), i.e. tumor cell clusters reaching not more than $0.2 \mathrm{~mm}$ in diameter, classified as nodal negative $(\mathrm{pN} 0[\mathrm{i}+])$, and micrometastases, which are defined as metastatic deposits larger than $0.2 \mathrm{~mm}$ in diameter but not larger than $2 \mathrm{~mm}$, classified as nodal positive (pN1mi) [52]. By the routine use of immunohistochemistry, an upstaging of $10 \%$ of the SLNB can be expected, but the clinical relevance of such occult metastases is doubtful. Non-sentinel node metastases are found in about $10 \%$ of patients with ITCs in the SLN and in $20-35 \%$ of patients with micrometastases in the SLN [53].
Therefore, the ASCO guideline published in 2005 for SLNB in early-stage breast cancer recommended completion ALND in the case of SLN micrometastases [50].

Today, the prognostic relevance of ITCs and micrometastases is negligible. The ACOSOG Z0010 trial included 5,210 patients with clinical $\mathrm{T} 1$ to T2N0M0 carcinomas treated with BCS and SLNB. Occult SLN metastases were present in $10.5 \%$ of the cases, but no differences in DFS and OS were seen [54]. The 10-year follow-up data of the NSABP B-32 trial (SLNB alone vs. SLN + ALND in SLN-negative patients) with prevalence of occult SLN metastases in $15.9 \%$ revealed a significant difference in DFS $(\mathrm{p}=0.01)$ and a nearly significant difference in OS $(\mathrm{p}=0.06)$. The locoregional recurrence was not significantly different between the occult and nonoccult metastases groups $(\mathrm{p}=0.52)$. However, the impact of occult metastatic nodal disease in this very large cohort $(\mathrm{n}=5,611)$ with a DFS hazard ratio (HR) of 1.02 and an OS HR of 1.09 is clinically non-significant, and the routine use of immunohistochemistry for SLNB is not recommended by the NSABP B-32 investigators [55, 56].

Galimberti et al. [57] published a retrospective study including 377 patients with a single micrometastatic SLN who did not undergo completion ALND. After 5 years, the OS reached $97.3 \%$ and an incidence of axillary recurrence of $1.6 \%$ was found. Finally, these data were confirmed by the prospective randomized IBCSG 23-01 trial [10]. Including patients with 1 or more micrometastatic SLN with no extracapsular extension, no differences between the treatment arms were seen for survival outcomes comparing completion ALND versus observation. Therefore, completion ALND in case of SLN micrometastases is no longer recommended [58].

\section{Involved SLNs and BCS}

The presentation of the prospective, multicentric ACOSOG Z0011 trial at the ASCO meeting 2010 was a landmark for the discussion on surgical options in $\mathrm{pN}+$ patients after SLNB. According to the protocol, nearly 900 patients with clinically T1/T2 cN0 cM0 breast cancer and BCS with metastatic involved SLNs (detected by routine hematoxylin and eosin staining) were randomized to no further axillary dissection or completion ALND [1]. The targeted enrollment was 1,900 women, but the trial closed earlier due to lower than expected accrual and event rates. After a median follow-up of 6.3 years there were no significant differences between the SLNB alone and SLNB plus ALND arms concerning the 5-year local recurrence rate $(1.6 \%$ vs. $3.1 \%)$, the 5 -year DFS $(83.9 \%$ vs. $82.2 \%)$, or the 5 -year OS $(92.5 \%$ vs. $91.8 \%)$. The local axillary recurrence rate was $0.9 \%$ for SLNB alone and $0.5 \%$ for SLNB + ALND [1, 2]. Because all patients were treated with opposing and tangential field irradiation, a local effect on the axilla could not be completely excluded, but it seems very unlikely in this dimension. 
The lower part of the axilla is irradiated during breast-conserving therapy and receives a nearly therapeutic dose depending on the upper limit of the tangential fields to the breast or chest wall. A meta-analysis by van Wely et al. [59] showed that external-beam radiation therapy (EBRT) to the breast was associated with a lower axillary recurrence rate compared to patients who did not receive EBRT as part of their initial therapy after negative SLNB ( $0.4 \%$ vs. $1.2 \%$; $\mathrm{p}<0.001)$. These data indicate that a proportion of the radiation therapy will be given to the residual axillary nodes after SLNB. Although it may not be considered as therapeutic dose, the dose delivered to the region in which the SLNs are normally found could well influence the natural evolution of residual tumor cells [59]. The updated German S3 guideline (July 2012) summarizes these facts: In cases with standard EBRT to the breast (50 Gy), a dose of 20-40 Gy is expected for the ipsilateral axillary levels [60].

In March 2011, the German Working Group Gynecological Oncology (AGO) Breast Group adapted the current guidelines according to the ACOSOG Z0011 findings. Completion ALND is no longer recommended (only ' + /-' grade of recommendation) in patients with positive sentinel nodes and in case of: cT1/2, cN0, less than 3 sentinel nodes involved, BCS plus tangential breast irradiation, no alternative ART, and adequate systemic therapy [23]. Although these results seem somewhat definitive and provide strong support for the abandonment of ALND for 'Z0011-eligible' patients, there are several concerns regarding the design, accrual, and data collection (details in $[6,61]$ ).

\section{Involved Sentinel Lymph Nodes and Mastectomy}

The ACOSOG Z0011 results have stimulated interest in the omission of completion ALND in other subgroups, such as total mastectomy patients. A previously discussed MSKCC paper focused on total mastectomy patients $(n=210)$ with positive SLNB who did not receive axillary-specific treatment $[62,63]$. Characteristics and outcomes were compared to similar patients who underwent BCS $(\mathrm{n}=325)$. At a median follow-up of 57.8 months, the 4-year locoregional failure rates were very low in both subgroups, without statistically significant differences between groups.

The MSKCC paper was not the first to suggest that lowrisk patients who undergo total mastectomy may avoid completion ALND after positive SLNB. However, none of the cited studies was sufficiently powered to analyze mastectomy patients separately [64, 65]. Bilimoria et al. [66] analyzed a large cohort of the National Cancer Data Base (1998-2005) including women with clinically node-negative breast cancer who underwent SLNB and who had identified nodal metastases (median follow-up, 63 months). One asset of this paper is the differentiation between microscopic $(0.2-2.0 \mathrm{~mm})$ and macroscopic nodal disease (> $2.0 \mathrm{~mm}$ ). Among 20,217 cases with SLNB alone, 3,757 patients were treated with mastectomy $(18.6 \%)$. A proportion of these patients received adjuvant radiation therapy after mastectomy $(n=795)$. On univariate analysis, there was no significant difference in the axillary recurrence rate between SLNB alone versus SLNB with completion ALND in patients with macroscopic nodal metastases $(1.0 \%$ vs. $1.2 \%)$ or microscopic nodal metastases ( $0.4 \%$ vs. $0.2 \%)$.

A prospective randomized trial for mastectomy patients with macrometastatic nodal disease after SLNB should be feasible after modification of the Z0011 design. As German specification, the issue of PMRT in cases with 1-2 involved SLNs could be incorporated in a randomization between SLNB alone versus PMRT with added axillary field. According to the St. Gallen 2013 consensus conference, the panel was nearly equally divided as to whether the Z0011 findings can also be applied to patients with mastectomy and 1-2 involved SLNs followed by PMRT, but was almost unanimous in the need for ALND if no PMRT was planned [67].

\section{Radiotherapy for Involved SLN}

Longtime follow-up data of clinical trials have shown that adjuvant radiotherapy after BCS decreases the risk of ipsilateral in-breast recurrence and distant recurrence, resulting in a significantly improved OS [68]. Radiotherapy after mastectomy in case of node-positive disease is well known to reduce local recurrences and improves OS by 6\% [69]. PMRT trials almost included radiation of regional axillary, medial supraclavicular, and internal mammary lymph nodes.

The National Cancer Institute of Canada Clinical Trials Group (NCIC-CTG) MA.20 trial evaluated the addition of regional nodal irradiation (RNI; 45 Gy in 25 fractions to the internal mammary, supraclavicular, and high axillary lymph nodes) to whole-breast irradiation (WBI) following BCS. The median follow-up was 62 months and 1,832 women (90\% node positive) were included. The results reported by Whelan et al. [11] demonstrated that additional RNI reduces the risk of isolated locoregional recurrence (94.5\% vs. 96.8\%) and improves DFS (84.0\% vs. $89.7 \%$ ). Additionally, there was a trend toward improvement in OS $(90.7 \%$ vs. $92.3 \%)$. However, the MA.20 trial is not yet published and shows apparently contradictory findings to other studies. The $2.3 \%$ recurrence rate in the ALND (control) arm at 5 years is almost 5 times higher than that seen after ALND in the ACOSOG Z0011 (0.5\%) or AMAROS (0.54\%) trials, and equal to what was seen in the NSABP B-04 trial $(2.5 \%)$ in the absence of systemic therapy, and raises questions about the contribution of the poor outcome in the control arm to the benefit of radiotherapy [7].

In the era of SLNB, the question arises whether ALND is necessary in case of positive SLNs. In the EORTC non-inferiority AMAROS trial, patients with early-stage breast cancer 
and positive SLN were randomized between ALND and ART. With a median follow-up of 6.1 years, the axillary recurrence rate was $0.54 \%(4 / 744)$ in the ALND arm and $1.03 \%$ (7/681) in the ART arm. The axillary recurrence rate in case of a negative SLNB was $0.8 \%$. The treatment arms did not show any significant differences regarding OS (93.3\% ALND vs. $92.5 \%$ ART; $p=0.34)$ and DFS (86.9\% ALND vs. $82.6 \%$ ART; $p=0.18)$. However, the rate of lymph edema was significantly lower in the ART subgroup [3].

According to the National Comprehensive Cancer Network (NCCN) guidelines there is no indication for ART besides macroscopic residual disease and the impossibility of surgical resection [22]. As a consequence from the AMAROS trial (17.4\% with mastectomy) for 'Z0011-ineligible' patients with mastectomy and positive SLNB, irradiation of the axillary nodes is a valid option instead of completion ALND.

\section{Ongoing SOUND Trial}

The European Institute of Oncology (EIO) of Milan, Italy, designed the SOUND trial, which is a prospective randomized multicentric study representing a further step to answer the following key questions: Do we really need to look for an SLN? Do we really need the information obtained by identifying and examining the SLN?

The eligibility and exclusion criteria have been published in detail by Gentilini and Veronesi [70]. Briefly, patients with small breast cancer (T1) who are candidates for BCS and have a clinically node-negative axilla will undergo an AUS in order to rule out an evident or suspicious nodal involvement. Patients with either negative FNA cytology of a single doubtful lymph node or with negative AUS will be eligible for randomization into 2 groups: SLNB (+ ALND in all cases with SLN macrometastases) versus no axillary surgical staging.

The EIO investigators defined distant DFS (DDFS) as the primary endpoint of the SOUND trial, with the assumption that reliable results can be obtained in a shorter period of time compared to OS. Overall, 1,560 women (780 per arm) will be enrolled to decide whether the observation group is not worse than the SLNB group, given a margin $\Delta$ of non-inferiority of $2.5 \%$ (maximum tolerable 5-year DDFS $=94 \%$ ) [70]. Officially, the first patient entered the SOUND trial in January 2012. So far (until December 2013), 375 patients have been randomized (O. Gentilini, personal communication).

\section{Planned INSEMA Trial}

The goal of the planned German/Austrian INSEMA study is to show that early-stage breast cancer patients with reduced extent of axillary surgery are not inferior regarding an invasive DFS (IDFS) outcome compared with the standard arm.

The inclusion criteria can be listed as follows:

- written informed consent prior to beginning BCS, including expected cooperation of the patients for follow-up

- histologically confirmed unilateral primary invasive carcinoma of the breast (core biopsy)

- age at diagnosis at least 35 years

- preoperative imaging techniques with estimated tumor size of $\leq 5 \mathrm{~cm}$ (iT1/iT2 irrespective of hormone sensitivity or HER2 status)

- clinically and sonographically tumor-free axilla prior to core biopsy (cN0/iN0)

- in cases with cN0 and iN1, a negative core biopsy or FNA cytology of the sonographically suspected lymph node is required before randomization

- no clinical evidence for distant metastasis (M0)

- planned BCS with postoperative standard external WBI The exclusion criteria are:

- secondary malignancy, except curatively treated basalioma of the skin and carcinoma in situ of the cervix

- time since core biopsy $>3$ months (optimal $<1$ month)

- previous and already (neoadjuvantly) treated invasive breast carcinoma

- histologically non-invasive breast carcinoma

- clinically T3/T4 or imaging T3/T4 tumors

- very young patients aged $<35$ years

- inadequate surgical treatment with histological incomplete resection (R1) of the invasive or intraductal tumor in the breast

- planned total mastectomy or secondary salvage mastectomy (primary care)

- planned intraoperative radiotherapy (e.g. intrabeam) or postoperative partial breast irradiation (e.g. multicatheter technique) alone; both procedures are allowed as boost techniques

- male patients

In this trial, patients with breast cancer smaller or equal to $5 \mathrm{~cm}$ (T1/T2), a node-negative axilla (clinically and/or per imaging), planned BCS, and age $\geq 35$ years can be recruited. Patients treated with mastectomy will be excluded due to the fact that (1) the majority of published prospective randomized trial data regarding omission of SLNB or completion ALND is limited to BCS and (2) the indication of PMRT is still linked to the number of involved lymph nodes.

Patients will be first randomized to either no axillary surgical intervention or axillary SLNB in a 1:4 allocation. Patients with SLNB and $\mathrm{pN}+(\mathrm{sn})$ status will be secondly randomized (1:1 ratio) to either SLNB alone or completion ALND in cases with less than 3 involved nodes (1 or 2 macrometastases). Patients with 3 or more macrometastatic SLNs should undergo completion ALND (fig. 1).

At 6,740 , the total number of patients to be randomized into the trial will be quite high due to the unequal-sample size 


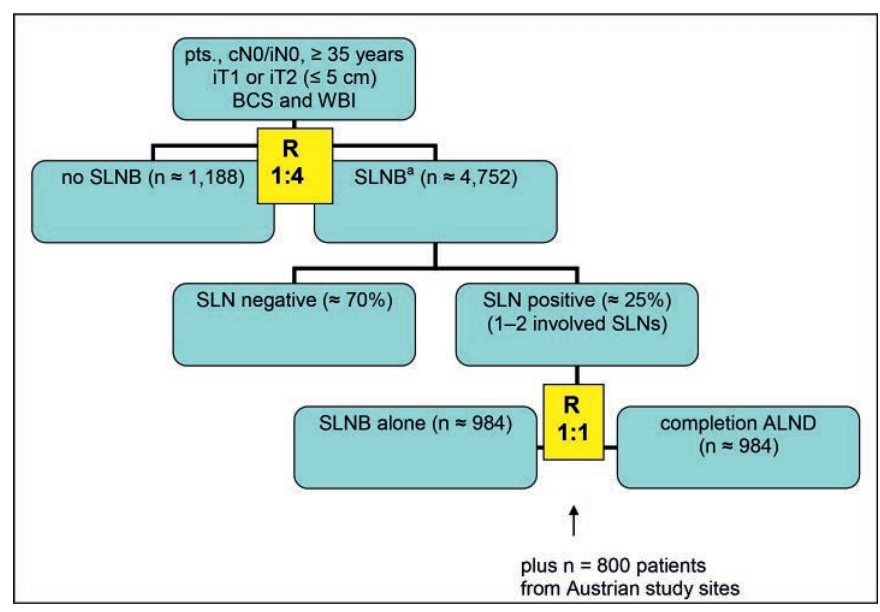

Fig. 1. Flow chart of the planned German-Austrian INSEMA trial ( $\mathrm{n}=5,940$ from German study sites).

pts $=$ Patients, $\mathrm{cN} 0=$ clinically nodal negative, $\mathrm{iN} 0=$ imaging nodal negative (if $\mathrm{cN} 0 / \mathrm{iN}+$ : a fine-needle aspiration or core biopsy should be done; cases with no evidence of tumor cells in the suspected lymph node can be recruited), iT1/2 = imaging tumor size, $\mathrm{BCS}=$ breast-conserving surgery, $\mathrm{WBI}=$ whole-breast irradiation, $\mathrm{SLNB}=$ sentinel lymph node biopsy, ALND = axillary lymph node dissection (for all cases with $>2$ involved sentinel lymph nodes), $\mathrm{R}=$ randomization (recruitment period 4 years; routine follow-up at least 5 years).

${ }^{a} 5 \%$ of all SLNB patients after the first randomization are to be expected as $\mathrm{pN}+(\mathrm{sn})$ with $>2$ involved sentinel lymph nodes.

design. Overall, 5,940 German patients will be enrolled for the entire protocol. In addition to the SOUND trial, the INSEMA design provides the potential to clarify some Z0011 problems: distribution of axillary isodoses with standard WBI, ignoring of patients with low tumor burden (ITCs, micrometastases) for the second randomization, and appropriate case numbers. To reach the calculated target of 1,968 patients for the second randomization, the Austrian study sites will recruit 800 patients exclusively for the Z0011 question. The accrual period during which patients enter the study is 48 months. During follow-up, patients will be assessed for disease recurrence according to standard clinical practice.

All study patients must receive CT-based WBI with 3-dimensional conformal radiation therapy (3DCRT) to the remaining breast (50 Gy in 25 fractions or $50.4 \mathrm{~Gy}$ in 28 fractions) delivered in supine position. A boost to the tumor bed is recommended according to the updated German S3 guideline (dose (10-)16 Gy). Although the ipsilateral axillary region is not included in the breast clinical target volume, it cannot be avoided that the delivered 3DCRT covers ipsilateral axillary levels within the final irradiated volume. To ana- lyze potential axillary involvement during WBI, accurate and consistent contouring of the ipsilateral axilla (levels I-III) is essential for an evaluation of the INSEMA cases using published Radiation Therapy Oncology Group (RTOG) consensus definitions (Breast Cancer Atlas, www.rtog.org). Postoperative systemic treatment should be based on local multidisciplinary tumor board recommendations according to the current German AGO and S3 guidelines [23, 60].

The University of Rostock is the 'sponsor' of the INSEMA trial. After the final decision of the board of directors in December 2013, the study is funded by a German Cancer Aid (Deutsche Krebshilfe) grant. Launch of the study is planned for May/June 2014 in Germany.

\section{Conclusions}

Currently, axillary surgery for breast cancer is considered as staging procedure that does not seem to influence the breast cancer mortality, since the risk of developing metastasis depends mainly on the biological behavior of the primary (seed-and-soil model) [71]. Based on this, the postsurgical therapy should be considered on the basis of biologic tumor characteristics rather than nodal involvement.

Women with breast cancer have benefitted greatly from a series of carefully performed randomized controlled trials focusing on axillary surgery. Each successive trial showed that less surgery was better in that outcomes were the same and less surgical intervention resulted in fewer surgical complications. A fundamental point in ongoing or planned trials abandoning axillary surgery is the question of how carefully 'clinically node-negative' patients can be defined.

A high rate of locoregional control can be achieved with multimodality therapy, even without ALND. Despite increasing evidence disfavoring ALND, it remains part of the widely recognized guidelines for breast cancer. The modern approach in breast cancer care, which includes more detailed screening diagnostics, pathological evaluation, improved planning of surgical and radiation therapy, and more effective systemic treatment, emphasizes the need for ongoing re-evaluation of the 'standard' locoregional therapy.

\section{Disclosure Statement}

We declare that there are no conflicts of interest related to this review.

\section{References}

1 Giuliano AE, McCall L, Beitsch P, Whitworth PW, Blumencranz P, Leitch AM, Saha S, Hunt KK, Morrow M, Ballman K: Locoregional recurrence after sentinel lymph node dissection with or without axillary dissection in patients with sentinel lymph node metastases. Ann Surg 2010;252:426-433.

2 Giuliano AE, Hunt KK, Ballman KV, Beitsch PD, Whitworth PW, Blumencranz PW, Leitch AM,
Saha S, McCall LM, Morrow M: Axillary dissection vs no axillary dissection in women with invasive breast cancer and sentinel node metastasis. JAMA 2011;305:569-575. 
3 Rutgers EJ, Donker M, Straver ME, Meijnen P, Van De Velde CJH, Mansel RE, et al.: Radiotherapy or surgery of the axilla after a positive sentinel node in breast cancer patients: final analysis of the EORTC AMAROS trial (10981/22023). J Clin Oncol 2013;31(suppl):abstr LBA1001.

4 Morrow M: It is not always necessary to do axillary dissection for $\mathrm{T} 1$ and $\mathrm{T} 2$ breast cancer - point. Cancer Res 2013;73:7151-7154.

5 Sabel MS: It is not always necessary to do axillary dissection for $\mathrm{T} 1$ and $\mathrm{T} 2$ breast cancer - reply to point. Cancer Res 2013;73:7155.

6 Sabel MS: The need for axillary lymph node dissection in T1/T2 breast cancer surgery - counterpoint. Cancer Res 2013;73:7156-7160.

7 Morrow M: The need for axillary lymph node dissection in T1/T2 breast cancer surgery - reply to counterpoint. Cancer Res 2013;73:7161.

8 Fisher B, Jeong JH, Anderson S, Bryant J, Fisher ER, Wolmark N: Twenty-five-year follow-up of a randomized trial comparing radical mastectomy, total mastectomy, and total mastectomy followed by irradiation. N Engl J Med 2002;347:567-575.

$\checkmark$ Krag DN, Anderson SJ, Julian TB, Brown AM, Harlow SP, Costantino JP, et al.: Sentinel-lymphnode resection compared with conventional axillary-lymph-node dissection in clinically node-negative patients with breast cancer: overall survival findings from the NSABP B-32 randomised phase 3 trial. Lancet Oncol 2010;11:927-933.

10 Galimberti V, Cole BF, Zurrida S, Viale G, Luini A, Veronesi P, et al.: Axillary dissection versus no axillary dissection in patients with sentinelnode micrometastases (IBCSG 23-01): a phase 3 randomised controlled trial. Lancet Oncol 2013; 14:297-305.

11 Whelan TJ, Olivotto I, Ackerman I, Chapman W, Chua B, et al.: NCIC-CTG MA.20: an intergroup trial of regional nodal irradiation in early breast cancer. J Clin Oncol 2011;29(suppl):abstr LBA1003.

12 Dengel LT, Van Zee KJ, King TA, Stempel M, Cody HS, El-Tamer M, et al.: Axillary dissection can be avoided in the majority of clinically nodenegative patients undergoing breast-conserving therapy. Ann Surg Oncol 2014;21:22-27.

13 Ibrahim-Zada I, Grant CS, Glazebrook KN, Boughey JC: Preoperative axillary ultrasound in breast cancer: safely avoiding frozen section of sentinel lymph nodes in breast-conserving surgery. J Am Coll Surg 2013;217:7-15.

14 Stachs A, Gode K, Hartmann S, Stengel B, Nierling U, Dieterich M, Reimer T, Gerber B: Accuracy of axillary ultrasound in preoperative nodal staging of breast cancer - size of metastases as limiting factor. SpringerPlus 2013;2:350.

15 Alvarez S, Añorbe E, Alcorta P, López F, Alonso I, Cortès I: Role of sonography in the diagnosis of axillary lymph node metastases in breast cancer: a systematic review. AJR Am J Roentgenol 2006; 186:1342-1348.

16 Houssami N, Ciatto S, Turner RM, Cody HS, Macaskill P: Preoperative ultrasound-guided needle biopsy of axillary nodes in invasive breast cancer. Ann Surg 2011;254:243-251.

17 Mainiero MB, Cinelli CM, Koelliker SL, Graves TA, Chung MA: Axillary ultrasound and fine-needle aspiration in the preoperative evaluation of the breast cancer patient: an algorithm based on tumor size and lymph node appearance. AJR Am J Roentgenol 2010;195:1261-1267.

-18 Esen G, Gurses B, Yilmaz MH, Ilvan S, Ulus S, Celik V, Farahmand M, Calay OO: Gray-scale and power Doppler US in the preoperative evaluation of axillary metastases in breast cancer patients with no palpable lymph nodes. Eur Radiol 2005;15: 1215-1223.

19 Peare R, Staff RT, Heys SD: The use of FDG-PET in assessing axillary lymph node status in breast cancer: a systematic review and meta-analysis of the literature. Breast Cancer Res Treat 2010;123: 281-290.

20 Mortellaro VE, Marshall J, Singer L, Hochwald SN, Chang M, Copeland EM, Grobmyer SR: Magnetic resonance imaging for axillary staging in patients with breast cancer. J Magn Reson Imaging 2009; 30:309-312.

21 Kaufmann M, von Minckwitz G, Mamounas EP, Cameron D, Carey LA, Cristofanilli M, et al.: Recommendations from an international consensus conference on the current status and future of neoadjuvant systemic therapy in primary breast cancer. Ann Surg Oncol 2012;19:1508-1516.

22 Gradishar WJ, Anderson BO, Blair SL, Burstein HJ, Cyr A, Elias AD, et al.: NCCN Clinical Practice Guidelines in Oncology (NCCN guidelines) Breast Cancer, version 1,2014. www.nccn.org.

23 Members of the German AGO Breast Committee: Diagnosis and Treatment of Patients with Primary and Metastatic Breast Cancer. Guidelines of the AGO Breast Committee 2013. www.ago-online.de

24 Kelly AM, Dwamena B, Cronin P, Carlos RC: Breast cancer sentinel node identification and classification after neoadjuvant chemotherapy: systematic review and meta analysis. Acad Radiol 2009; 16:551-563.

25 Xing Y, Foy M, Cox DD, Kuerer HM, Hunt KK, Cormier JN: Meta-analysis of sentinel lymph node biopsy after preoperative chemotherapy in patients with breast cancer. Br J Surg 2006;93:539-546.

26 van Deurzen CH, Vriens BE, Tjan-Heijnen VC, van der Wall E, Albregts M, van Hilligersberg R, Monninkhof EM, van Diest PJ: Accuracy of sentinel node biopsy after neoadjuvant chemotherapy in breast cancer patients: a systematic review. Eur J Cancer 2009;45:3124-3130.

27 Tan VK, Goh BK, Fook-Chong S, Khin LW, Wong WK, Yong WS: The feasibility and accuracy of sentinel lymph node biopsy in clinically nodenegative patients after neoadjuvant chemotherapy for breast cancer: a systematic review and metaanalysis. J Surg Oncol 2011;104:97-103.

28 Morrow M, Dang CT: Sentinel node biopsy after neoadjuvant chemotherapy: a new standard for patients with axillary metastases? JAMA 2013; 310:1449-1450.

29 Kuehn T, Bauerfeind I, Fehm T, Fleige B, Hausschild M, Helms G, et al.: Sentinel-lymphnode biopsy in patients with breast cancer before and after neoadjuvant chemotherapy (SENTINA): a prospective, multicentre cohort study. Lancet Oncol 2013;14:609-618.

30 Boughey JC, Suman VJ, Mittendorf EA, Ahrendt GM, Wilke LG, Taback B, et al.: Sentinel lymph node surgery after neoadjuvant chemotherapy in patients with node-positive breast cancer: the ACOSOG Z1071 (Alliance) clinical trial. JAMA 2013;310:1455-1461.

31 Giuliano AE, Kirgan DM, Guenther JM, Morton DL: Lymphatic mapping and sentinel lymphadenectomy for breast cancer. Ann Surg 1994;220:391-398.

32 Canavese G, Catturich A, Vecchio C, Tomei D, Gipponi M, Villa G, Carli F, Bruzzi P, Dozin B: Sentinel node biopsy compared with complete axillary dissection for staging early breast cancer with clinically negative lymph nodes: results of randomized trial. Ann Oncol 2009;20:1001-1007.
33 Purushotham AD, Upponi S, Klevesath MB, Bobrow L, Millar K, Myles JP, Duffy SW: Morbidity after sentinel lymph node biopsy in primary breast cancer: results from a randomized controlled trial. J Clin Oncol 2005;23:4312-4321.

34 Veronesi U, Viale G, Paganelli G, Zurrida S, Luini A, Galimberti V, et al.: Sentinel lymph node biopsy in breast cancer: ten-year results of a randomized controlled study. Ann Surg 2010;251:595600.

35 Fleissig A, Fallowfield LJ, Langridge CI, Johnson L, Newcombe RG, Dixon JM, Kissin M, Mansel RE: Post-operative arm morbidity and quality of life. Results of the ALMANAC randomised trial comparing sentinel node biopsy with standard axillary treatment in the management of patients with early breast cancer. Breast Cancer Res Treat 2006;95: 279-293.

36 Zavagno G, De Salvo GL, Scalco G, Bozza F, Barutta L, Del Bianco P, Renier M, Racano C, Carraro P, Nitti D; GIVOM Trialists: A randomized clinical trial on sentinel lymph node biopsy versus axillary lymph node dissection in breast cancer: results of the Sentinella/GIVOM trial. Ann Surg 2008;247:207-213.

37 Gill G; SNAC Trial Group of the Royal Australasian College of Surgeons (RACS) and NHMRC Clinical Trials Centre: Sentinel-lymph-node-based management or routine axillary clearance? Oneyear outcomes of sentinel node biopsy versus axillary clearance (SNAC): a randomized controlled surgical trial. Ann Surg Oncol 2009;16:266-275.

38 Wang Z, Wu LC, Chen JQ: Sentinel lymph node biopsy compared with axillary lymph node dissection in early breast cancer: a meta-analysis. Breast Cancer Res Treat 2011;129:675-689.

39 Rao R, Euhus D, Mayo HG, Balch C: Axillary node interventions in breast cancer: a systematic review. JAMA 2013;310:1385-1394.

40 De Gournay E, Guyomard A, Coutant C, Boulet S, Arveux P, Causeret S, et al.: Impact of sentinel biopsy on long-term quality of life in breast cancer patients. Br J Cancer 2013;109:2783-2791.

41 Toesca A, Luini A, Veronesi P, Intra M, Gentilini $\mathrm{O}$ : Sentinel lymph node biopsy in early breast cancer: the experience of the European Institute of Oncology in special clinical scenarios. Breast Care 2011;6:208-214.

42 Kothari MS, Rusby JE, Agusti AA, MacNeill FA: Sentinel lymph node biopsy after previous axillary surgery: a review. Eur J Surg Oncol 2012;38:8-15.

43 International Breast Cancer Study Group, Rudenstam CM, Zahrieh D, Forbes JF, Crivellari D, Holmberg SB, Rey P, et al.: Randomized trial comparing axillary clearance versus no axillary clearance in older patients with breast cancer: first results of International Breast Cancer Study Group Trial 10-93. J Clin Oncol 2006;24:337-344.

44 Agresti R, Martelli G, Sandri M, Tagliabue E, Carcangiu ML, Maugeri I, et al.: Axillary lymph node dissection versus no dissection in patients with T1N0 breast cancer: a randomized clinical trial (INT09/98). Cancer 2013; doi: 10.1002/ cncr.28499.

45 Martelli G, Boracchi P, Ardoino I, Lozza L, Bohm S, Vetrella G, Agresti R: Axillary dissection versus no axillary dissection in older patients with T1N0 breast cancer: 15-year results of a randomized controlled trial. Ann Surg 2012;256:920-924.

46 Johansen H, Kaae S, Jensen MB, Mouridsen HT: Extended radical mastectomy versus simple mastectomy followed by radiotherapy in primary breast cancer. A fifty-year follow-up to the Copen- 
hagen Breast Cancer randomised study. Acta Oncol 2008;47:633-638.

47 Veronesi U, Orecchia R, Zurrida S, Galimberti V, Luini A, Veronesi $\mathrm{P}$, et al.: Avoiding axillary dissection in breast cancer surgery: a randomized trial to assess the role of axillary radiotherapy. Ann Oncol 2005;16:383-388.

48 Louis-Sylvestre C, Clough K, Asselain B, Vilcoq JR, Salmon RJ, Campana F, Fourquet A: Axillary treatment in conservative management of operable breast cancer: dissection or radiotherapy? Results of a randomized study with 15 years of follow-up. J Clin Oncol 2004;22:97-101.

49 Evans SB, Gass J, Wazer DE: Management of the axilla after the finding of a positive sentinel lymph node: a proposal for an evidence-based risk-adapted algorithm. Am J Clin Oncol 2008;31:293-299.

50 Lyman GH, Giuliano AE, Sommerfield MR, Benson AB 3rd, Bodurka DC, Burstein HJ, et al. American Society of Clinical Oncology guideline recommendations for sentinel lymph node biopsy in early-stage breast cancer. J Clin Oncol 2005; 23:7703-7720.

-51 Cserni G, Amendoeira I, Apostolikas N, Bellocq JP, Bianchi S, Bussolati G, et al.: Pathological work-up of sentinel lymph nodes in breast cancer. Review of current data to be considered for the formulation of guidelines. Eur J Cancer 2003;39:1654-1667.

52 Green FL, Page DL, Fleming ID: American Joint Committee on Cancer Staging Manual, ed 6. Philadelphia, Springer, 2002.

53 McCready DR, Yong WS, Ng AK, Miller N, Done S, Youngson B: Influence of the new AJCC breast cancer staging system on sentinel lymph node positivity and false-negative rates. J Natl Cancer Inst 2004;96:873-875.

54 Giuliano AE, Hawes D, Ballmann KV, Whitworth PW, Blumencranz PW, Reintgen DS, Morrow M, Leitch AM, Hunt KK, McCall LM, Abati A Cote R: Association of occult metastases in sentinel lymph nodes and bone marrow with survival among women with early-stage invasive breast cancer. JAMA 2011;306:385-393.

55 Julian TB, Anderson SA, Krag DN, Harlow SP, Costantino JP, Ashikaga T, Weaver DL, Mamounas EP, Wolmark N; National Surgical Adjuvant Breast and Bowel Project: 10-yr followup results of NSABP B-32, a randomized phase III clinical trial to compare sentinel node resection (SNR) to conventional axillary dissection (AD) in clinically node-negative breast cancer patients. J Clin Oncol 2013;31(suppl):abstr 1000.
56 Weaver DL, Ashikaga T, Krag DN, Skelly JM, Anderson SJ, Harlow SP, Julian TB, Mamounas EP, Wolmark N: Effect of occult metastases on survival in node-negative breast cancer. $\mathrm{N}$ Engl $\mathrm{J}$ Med 2011;364:412-421.

57 Galimberti V, Botteri E, Chifu C, Gentilini O, Luini A, Intra M, et al.: Can we avoid axillary dissection in the micrometastatic sentinel node in breast cancer? Breast Cancer Res Treat 2012; 131:819-825.

58 Goldhirsch A, Wood WC, Coates AS, Gelber RD, Thürlimann B, Senn HJ: Strategies for subtypes dealing with the diversity of breast cancer: highlights of the St. Gallen International Expert Consensus on the Primary Therapy of Early Breast Cancer 2011. Ann Oncol 2011;22:1736-1747.

59 van Wely BJ, Teerenstra S, Schinagl DAX, Aufenacker TJ, de Wilt JH, Strobbe LJ: Systematic review of the effect of external beam radiation therapy to the breast on axillary recurrence after negative sentinel lymph node biopsy. Br J Surg 2011;98:326-333.

60 Interdisziplinäre S3-Leitlinie für die Diagnostik, Therapie und Nachsorge des Mammakarzinoms, Langversion 3.0, Aktualisierung 2012. www.krebsgesellschaft.de/download/ S3_Brustkrebs_Update_2012_Langversion.pdf.

61 Latosinsky S, Berrang TS, Cutter CS, George R, Olivotto I, Julian TB, Hayashi A, Baliski C, Croshaw RL, Erb KM, Chen J: CAGS and ACS Evidence Based Reviews in Surgery. 40. Axillary dissection versus no axillary dissection in women with invasive breast cancer and sentinel node metastasis. Can J Surg 2012;55:66-69.

62 Milgrom S, Cody H, Tan L, Morrow M, Pesce C, Setton J, Rogers K, Arnold B, Eaton A, Catalano J, McCormick B, Powell S, Ho A: Characteristics and outcomes of sentinel node-positive breast cancer patients after total mastectomy without axillary-specific treatment. Ann Surg Oncol 2012; 19:3762-3770.

63 Reimer T: Axillary resection - hotly debated after Z0011. Breast Care 2012;7:341-343.

64 Naik AM, Fey J, Gemignani M, Heerdt A, Montgomery L, Petrek J, Port E, Sacchini V, Sclafani L, VanZee K, Wagman R, Borgen PI, Cody HS 3rd: The risk of axillary relapse after sentinel lymph node biopsy breast cancer is comparable with that of axillary lymph node dissection. A follow-up study of 4008 procedures. Ann Surg 2004;240:462-471.
5 Hwang RF, Gonzalez-Angulo AM, Yi M, Buchholz TA, Meric-Bernstam F, Kuerer HM, Babiera GV, Tereffe W, Liu DD, Hunt KK: Low locoregional failure rates in selected breast cancer patients with tumor-positive sentinel lymph nodes who do not undergo completion axillary dissection. Cancer 2007;110:723-730.

66 Bilimoria KY, Bentrem DJ, Hansen NM, Bethke KP, Rademaker AW, Ko CY, Winchester DP, Winchester DJ: Comparison of sentinel lymph node biopsy alone and completion axillary lymph node dissection for node-positive breast cancer. J Clin Oncol 2009;27:2946-2953.

67 Goldhirsch A, Winer EP, Coates AS, Gelber RD, Piccart-Gebhart M, Thürlimann B, Senn HJ Personalizing the treatment of women with early breast cancer: highlights of the St. Gallen International Expert Consensus on the Primary Therapy of Early Breast Cancer 2013. Ann Oncol 2013; 24:2206-2223.

68 Darby S, McGale P, Correa C, Taylor C, Arriagada R, Clarke M, Cutter D, Davies C, Ewertz M, Godwin J, Gray R, Pierce L, Whelan T, Wang Y, Peto R; Early Breast Cancer Trialists' Collaborative Group (EBCTCG): Effect of radiotherapy after breast-conserving surgery on 10-year recurrence and 15-year breast cancer death: metaanalysis of individual patient data for 10,801 women in 17 randomised trials. Lancet 2011; 378:1707-1716.

69 Clarke M, Collins R, Darby S, Davies C, Elphinstone P, Evans E, Godwin J, Gray R, Hicks C, James S, MacKinnon E, McGale P, McHugh T, Peto R, Taylor C, Wang Y; Early Breast Cancer Trialists' Collaborative Group (EBCTCG): Effects of radiotherapy and of differences in the extent of surgery for early breast cancer on local recurrence and 15-year survival: an overview of the randomised trials. Lancet 2005;366:2087-2106.

70 Gentilini O, Veronesi U: Abandoning sentinel lymph node biopsy in early breast cancer? A new trial in progress at the European Institute of Oncology of Milan (SOUND: Sentinel node vs Observation after axillary UltraSouND). Breast 2012;21:678-681.

71 Engel J, Lebeau A, Sauer H, Holzel D: Are we wasting our time with the sentinel technique? Fifteen reasons to stop axilla dissection. Breast 2006;15:452-455. 